\title{
MANIFESTAÇÕES RELIGIOSAS DOS ESTUDANTES DO CURSO DE SERVIÇO SOCIAL: UM ESTUDO A PARTIR DOS TRABALHOS DE CONCLUSÃO DE CURSO
}

\author{
Julia Mirian Teruel \\ Silva, Claudia Neves
}

\section{RESUMO}

Este trabalho tem caráter documental, e nos propomos a realizar uma análise das dedicatórias dos Trabalhos de Conclusão de curso elaborados pelos estudantes do Curso de Serviço Social da Universidade Estadual de Londrina entre os anos de 2010 a 2013, com o objetivo de analisar as dedicatórias que remetam a algum tipo de fé ou crença. Dando continuidade a uma pesquisa já em andamento, sobre Religião e Religiosidade dentro da UEL, a análise das dedicatórias dos Tcc's está sendo mais uma forma de verificar e analisar a presença da religiosidade na vida e no cotidiano desses jovens universitários. Além dos TCC'S realizamos algumas entrevistas com alunos do quarto ano de Serviço Social, delimitando uma amostra por conveniência, uma vez que não é possível entrevistar a todos. Também realizamos observações participantes em celebrações religiosas e observações na própria sala de aula onde os alunos assumem falas e posturas que deixam transparecer suas crenças e valores.

Palavras-Chaves: Serviço Social; Religião; Trabalho de Conclusão de Curso

\section{INTRODUÇÃO}

A religião e a religiosidade estão muito presentes no interior do curso de Serviço Social, levando em consideração que esse resquício religioso vem de seu surgimento, ou seja, a religião está enraizada no Serviço Social.

Desta maneira, esse trabalho discutira a religiosidade dos alunos de Serviço Social da Universidade Estadual De Londrina, mais especificamente os alunos de 4 ano, uma vez que nosso objeto principal de pesquisa serão os Trabalhos de Conclusão de Curso. Analisaremos as dedicatórias dos Tcc's do ano de 2010 a 2013, analisando as menções a Deus e a qualquer tipo de manifestação religiosa.

Exploraremos também as entrevistas realizadas com os alunos de Serviço Social, acerca da sua religião e de sua fé. Outro instrumento utilizado para a pesquisa foram as redes sociais onde analisamos páginas de teor religioso.

Dessa maneira, nos aprofundamos nas categorias de estudo que envolvem a religião e trouxemos aqui alguns conceitos e aprofundamentos acerca das temáticas que envolvem a religião no meio universitário.

Essa pesquisa tem como enfoque a religião e a religiosidade dos alunos do curso de Serviço Social da Universidade Estadual de Londrina. Surgindo para verificar e analisar esses vestígios de religião e religiosidade que encontramos nas salas de aula, vestígios estes que se manifestam através das falas e posturas identificadas em sala.

$\mathrm{O}$ interesse pela temática vem da falta de abordagem em meio aos fatos que estão postos, na medida em que nos deparamos com um Serviço Social ainda com resquícios religiosos, visto pelo senso comum como ajuda e filantropia. Muitos alunos 


\section{SEMINÁRIO DE PESQUISA EM CIÊNCIAS HUMANAS - SEPECH \\ Humanidades, Estado e desafios didático-científicos \\ Londrina, 27 a 29 de julho de 2016}

que ingressam no curso possuem ligação com a Igreja, e devido a essa ligação escolhem o Serviço Social para terem a oportunidade de levar para a profissão valores e conceitos trazidos de sua religiosidade.

Ao longo de quatro anos de formação essa concepção e até mesmo esses valores podem ser modificados ou desconstruídos. Mas ao analisarmos os TCCS poderemos perceber que de alguma maneira esta religiosidade ainda está ali, manifestada em um agradecimento ou em uma dedicatória, o que pode parecer pequeno, mas que não deixa de descaracterizar uma manifestação de sua fé.

Para a concretização da pesquisa, utilizamos tanto da pesquisa quantitativa, quanto da qualitativa. Foram realizadas entrevistas com $10 \%$ dos estudantes do quarto ano do curso de Serviço Social, com o objetivo de verificar se ainda vivenciam alguma religiosidade.

Outro instrumento utilizado pela pesquisa foi a observação participante, realizada durante 12 meses, dentro e fora da Universidade Estadual de Londrina, visitamos instituições religiosas, grupos de orações realizados dentro do campus universitário e cotidianamente realizamos observações dentro da própria sala de aula, onde se notou fortes elementos religiosos por parte dos próprios estudantes e também de professores, afirmando ou negando a religiosidade.

Como fonte de pesquisa também foram exploradas as redes sociais onde analisamos fanpages, blogs e canais religiosos do youtube, essas analises foram realizadas em Julho de 2015, e podemos observar que esses canais e paginas só vem crescendo e ganhando mais seguidores.

Mas o principal instrumento dessa pesquisa foram as dedicatórias dos trabalhos de conclusão de curso, trabalhos realizados no final da graduação pelos alunos. Analisamos todas as dedicatórias e agradecimentos desse trabalho e constatamos a presença de algum tipo de religiosidade nestes trabalhos, caracterizando uma pesquisa Documental, realizada a partir de documentos cientificamente reconhecidos

\section{RELIGIÃO E SUAS SUBJETIVIDADES}

Religiosidade é algo pessoal e particular, pois cada indivíduo pode manifestar a sua religiosidade de diferentes jeitos e maneiras, ou seja, são manifestações pessoais de fé, caracterizada por valores e crenças espirituais particulares. Necessariamente a religiosidade precisa contar com uma religião, que apesar na semelhança nos nomes são coisas diferentes...

E a partir dessa definição de religião, Silva (2008) também nos traz um pouco mais sobre o conceito de religiosidade.

Partimos do pressuposto de que a religiosidade, entendida como manifestação pessoal de fé, em uma busca por experiências e valores que transcendam a dimensão material e corporal, dá sentido à existência do indivíduo no mundo e equilíbrio para os diferentes aspectos da vida (social, afetivo, emocional, espiritual), determinando dessa forma, o comportamento e as ações deste indivívuo e mesmo de uma coletividade. 


\section{SEMINÁRIO DE PESQUISA EM CIÊNCIAS HUMANAS - SEPECH \\ Humanidades, Estado e desafios didático-científicos \\ Londrina, 27 a 29 de julho de 2016}

Visto que a fé ainda é um elemento presente na vida desses jovens, e que a graduação, ou seja, quatro anos de formação acadêmica não conseguiram enfraquecer essa religiosidade, presumimos que esses estudantes que estão se formando e saindo da faculdade, carregam seus princípios com base em valores religiosos.

Já que estamos falando da religiosidade manifestada dentro da Universidade, estamos falando de juventude, vale aqui explorar um pouco do conceito do que é ser jovem e alguns fatores que essa juventude implica.

A juventude é considerada por Canezin (2002) uma fase complicada, é caracterizada como um período de transição, onde acontece a passagem para a vida adulta, onde se passa a ter mais responsabilidade, compromissos e novos desafios.

Ainda segundo Canezin (2002, p. 60), a juventude é vista, como um período de transição do desenvolvimento humano, fase de adaptação, ou seja, período em que o indivíduo, não é mais criança e também é não adulto, passando por um período de transitoriedade.

Podemos considerar a Juventude também como um período de escolhas e decisões, como por exemplo a escolha de uma profissão, incluindo também a construção estilos, crenças, ideias, modos de pensar e agir, ou seja, todas as mudanças que vão que constituindo a identidade do Jovem.

Muitas pessoas prolongam seu período de Juventude, não querem assumir responsabilidades, falam, se vestem e se portam como um jovem e esbanjam de todas as características que definem e caracterizam a juventude, sem se preocupar com a idade ou com as responsabilidades vindas com o tempo e com os encargos da vida adulta.

Não é curioso considerarmos que sendo o jovem sujeito de inúmeras mudanças, possibilidades e alternativas a seu alcance ele opte justamente por seguir a uma religião, que muitas vezes vem limitar, impor regras de como agir, de como se portar, do que se deve ou não ser feito?

\section{APRESENTAÇÃO E ANÁLISE DOS DADOS}

Fazer uma dedicatória ou um agradecimento a Deus, ou para outras divindades religiosas vem a caracterizar a presença de algum tipo de Fé ou de crença, o que vem a afirmar ou reforçar o que observamos em sala de aula. É significativa a presença dessa religiosidade nas falas e nos discursos desses jovens, colocações e opiniões. Diante da analise realizada constatamos que $95 \%$ dos alunos fizeram algum tipo de agradecimento ou dedicatória a Deus em seu TCC.

Tabela 1: Dedicatórias e agradecimentos - TCCs 


\section{SEMINÁRIO DE PESQUISA EM CIÊNCIAS HUMANAS - SEPECH \\ Humanidades, Estado e desafios didático-científicos \\ Londrina, 27 a 29 de julho de 2016}

\section{ANÁLISE DOS TCC'S}

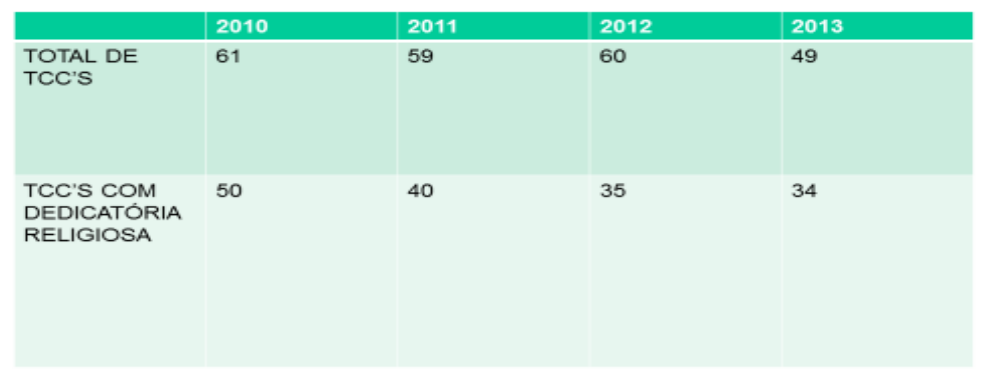

Fonte: TCCs do Curso de Serviço Socia - UEL analisados:

Citaremos alguns dos agradecimentos e dedicatórias encontradas nos tccs

Primeiramente quero agradecer a Deus, por ter me dado força, sabedoria e paciência nesses quatro anos de faculdade. E a Nossa Senhora pela intercessão na fase final deste trabalho.(2010)

Primeiramente quero agradecer a Deus, por ter me dado força, sabedoria e paciência nesses quatro anos de faculdade. E a Nossa Senhora pela intercessão na fase final deste trabalho. (2012)

Depois de analisar as dedicatórias e os agradecimentos dos TCC'S do curso de Serviço Social, dos anos de 2010,2011 e 2012, percebemos que a fé é presente na vida desses universitários. Como já analisamos acima, acontece que muitas vezes o Jovem se afasta das instituições religiosas, as vezes deixam seus serviços e afazeres de lá, por falta de tempo ou por outras inúmeras consequências ocasionadas pela correria do dia- a dia, mas mesmo diante desses fatores a fé não se enfraquece.

Muitas vezes essa fé é alicerçada por tradições familiares, valores e princípios que não são destruídos e abandonados facilmente.

Percebemos que essa tradição familiar é um fator muito influente na religiosidade destes jovens, pois fica evidente que a religião é algo que está intrínseco na vida e no cotidiano destes.

Gráfico: Motivações 


\section{SEMINÁRIO DE PESQUISA EM CIÊNCIAS HUMANAS - SEPECH \\ Humanidades, Estado e desafios didático-científicos \\ Londrina, 27 a 29 de julho de 2016}

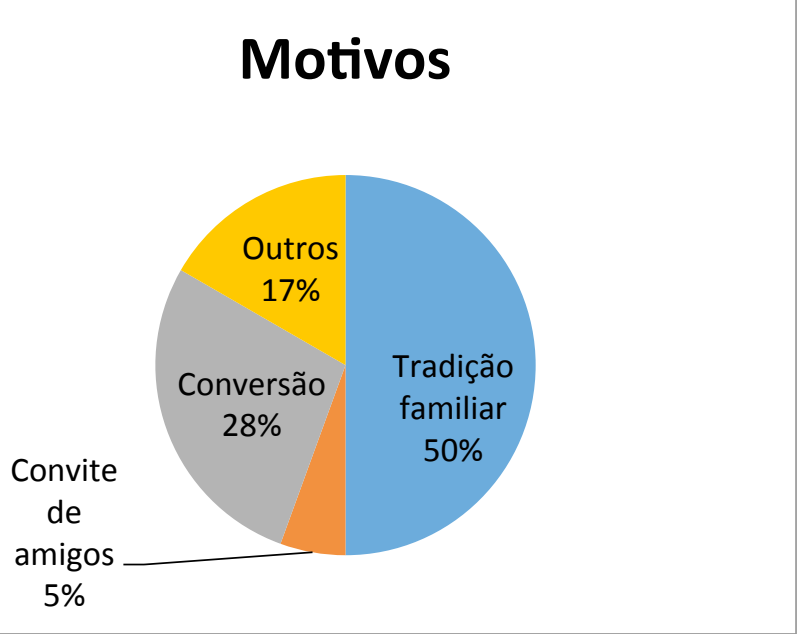

Fonte: Questionários aplicados em 2012 - UEL

Como demonstra o gráfico, essa tradição familiar é algo que não podemos negar, ou seja essa fé é transmitida pelos valores da família, pela religião da família, e vem sendo repassada e reproduzida de geração em geração, o que é curioso, é perceber que mesmo depois de adultos, estes jovens continuam optando e escolhendo pelas tradições religiosas.

Este trabalho evidencia um pouco sobre essa escolha, e sobre essa vivencia religiosa dos Jovens. Acrescentando aqui nossas observações feitas ao decorrer da pesquisa, no interior da sala de aula, e também do universo acadêmico em si, incluindo os grupos de oração Gou e Pocket, grupos que acontecem no interior da Universidade e conta com a participação dos jovens e também de servidores, que esses valores religiosos encontram espaço até mesmo na correria do dia dia, em um contexto acadêmico e dito laico.

Assim as manifestações e demonstrações de fé podem vir das mais diferentes formas. Dedicar um trabalho, ou fazer um agradecimento a Deus, por algo que demandou trabalho e dedicação pode ser considerado um indicador pequeno, mas somando com as falas, e com as manifestações de fé analisadas nas demais áreas da pesquisa, consideramos essas dedicatórias e agradecimentos fatores que vem a reafirmar que esta religiosidade não perde sua força ao longo do processo de formação acadêmica. E mais ainda, essa religiosidade ganha força, em meio aos desafios e dificuldades ocasionadas pelas dificuldades encontradas no dia dia acadêmico.

Os trabalhos de conclusão de curso, são trabalhos extensos e complexos, exige do aluno dedicação, atenção, tempo e comprometimento, ao decorrer da construção deste, os alunos se deparam com inúmeras dificuldades, causando tensão e nervosismo. Diante desses fatores os estudantes recorrem a tudo aquilo que os fazem bem, algo que alivie essa tenção e os de energia e forças para enfrentar toda essa tensão e nervosismos ocasionados pelos afazeres do dia dia, somando com a construção deste trabalho. É nesse cenário que encaixamos a religiosidade expressa nas dedicatórias e agradecimentos destes trabalhos.

"Agradeço primeiramente a Deus pelo amor incondicional que me permitiu vencer mais essa etapa da minha vida." 


\section{SEMINÁRIO DE PESQUISA EM CIÊNCIAS HUMANAS - SEPECH \\ Humanidades, Estado e desafios didático-científicos \\ Londrina, 27 a 29 de julho de 2016}

"Primeiramente agradeço a Deus, por estar ao meu lado em todos os momentos, sempre atendendo minhas súplicas, me concedendo a força e a sabedoria para superar os desafios impostos pela vida."

"Primeiramente, a Deus, O CRIADOR DE TUDO, obrigada pela vida e por sempre colocar em meu caminho as pessoas certas e na hora certa."

"Agradeço ao Papai do céu, por ter estado comigo, me dado forças, mesmo quando as dificuldades da vida me afastaram dele, Ele estava sempre guiando o meu caminho e os meus passos. "

Estas são algumas das dedicatórias e agradecimentos encontrados nos trabalhos analisados, fica evidente que os estudantes recorrem a fé e a religiosidade para terem forças e energia para a realização e conclusão dos trabalhos.

Em meio a esse ambiente acadêmico os jovens também relatam nas entrevistas feitas para agregar a pesquisa, que muitas vezes sofrem preconceito por viveram essa religiosidade dentro da universidade.

Esses preconceitos vêm de outros amigos, colegas de classe ou até mesmo de professores; mas essas manifestações de preconceito não intimidam ou enfraquecem tal religiosidade, não é difícil encontrarmos ao andar pelos campos jovens vestindo camisetas e colares que remetam a algum tipo de religiosidade.

Esse engajamento em atividades religiosas nos desperta muita curiosidade, uma vez que essas atividades requerem tempo e dedicação, em meio a todas as atividades do dia a dia, como, faculdade, estagio, trabalhos acadêmicos e afins os jovens ainda se engajam nesses movimentos religiosos.

Esse fator vem reforçar mais uma vez essa religiosidade, que vem se mostrando cada vez mais forte e fundamentada seja ela por tradições ou por conversões que se dão pelos mais diversos motivos.

\section{CONCLUSÃO}

Diante dos dados e dos apontamentos da pesquisa, nos deparamos com uma religiosidade que possui uma força em meio aos jovens, essa aceitação e adesão a esses movimentos religiosos despertou em nós, pesquisadores, a curiosidade de como esse fenômeno se manifesta, dessa maneira realizamos um trabalho de pesquisa que nos levou a constatar que a religiosidade em meio aos jovens é algo que está presente, e precisa ser discutida. Esse trabalho de pesquisa foi realizado justamente para abrir um espaço para essa discussão.

\section{REFERENCIAS}

http://tede.biblioteca.ucg.br/tde busca/arquivo.php?codArquivo=25

HALL, Stuart. Identidade cultural na pós - modernidade. Rio de Janeiro: DP\&A, 2004. 


\section{SEMINÁRIO DE PESQUISA EM CIÊNCIAS HUMANAS - SEPECH \\ Humanidades, Estado e desafios didático-científicos \\ Londrina, 27 a 29 de julho de 2016}

BAUMAN, Z. Individualidade. In: Modernidade Líquida. Rio de Janeiro: Jorge Zahar Editora,

http://www.pucpr.br/eventos/educere/educere2009/anais/pdf/3399 1932.pdf

http://www.angelfire.com/sk/holgonsi/hall1.html

http://pt.slideshare.net/cleber2511/neotomismo-e-servio-social acesso em 09-05-16

file://C:/Users/Julia/Downloads/3839-12873-1-PB.pdf acesso em 11-05-2016 